\title{
Laboratory environmental factors and pain behavior: the relevance of unknown unknowns to reproducibility and translation
}

\author{
Jeffrey S Mogil
}

The poor record of basic-to-clinical translation in recent decades has led to speculation that preclinical research is "irreproducible", and this irreproducibility in turn has largely been attributed to deficiencies in reporting and statistical practices. There are, however, a number of other reasonable explanations of both poor translation and difficulties in one laboratory replicating the results of another. This article examines these explanations as they pertain to preclinical pain research. I submit that many instances of apparent irreproducibility are actually attributable to interactions between the phenomena and interventions under study and "latent" environmental factors affecting the rodent subjects. These environmental variables - often causing stress, and related to both animal husbandry and the specific testing context-differ greatly between labs, and continue to be identified, suggesting that our knowledge of their existence is far from complete. In pain research in particular, laboratory stressors can produce great variability of unpredictable direction, as stress is known to produce increases (stress-induced hyperalgesia) or decreases (stress-induced analgesia) in pain depending on its parameters. Much greater attention needs to be paid to the study of the laboratory environment if replication and translation are to be improved.

Ever since the publication in 2011-2012 of two front-of-themagazine pieces by Prinz et al. ${ }^{1}$ and Begley and Ellis ${ }^{2}$, the research world has been rocked by accusations of the "irreproducibility" of preclinical research. Both of these articles described, anecdotally, the inability of pharmaceutical preclinical testing units to reproduce experiments by academic laboratories published in the scientific literature. These surveys were widely reported on in the media (e.g., ref. 3), and their pessimistic message was embraced by funding agencies ${ }^{4}$ and journal editors ${ }^{5}$. The desire for a more systematic approach to the issue yielded high-profile "reproducibility projects" in both psychology ${ }^{6}$ and cancer"; the former has been published and confirmed that large proportions of published research findings cannot be clearly reproduced by independent laboratories. A recent survey of preclinical scientists revealed that $52 \%$ think there is a "significant crisis".

This being said, it is hard to decide whether something in science has actually changed, or is "broken", or whether the apparent epidemic of irreproducibility is simply due to more attention being paid to the topic against a backdrop of the (undeniably) poor translational success of recent decades in drug development ${ }^{9}$.
Those commenting on irreproducibility have most often attributed it to poor experimental design, poor reporting of methods and results (for example, missing statements about blinding and randomization), various types of bias, investigator misconduct, and misuse of statistics ${ }^{10}$. I believe that all of these things occur. I would argue, however, that the current state of affairs is certainly no worse than when I started in science 25 years ago, and almost certainly better. At the beginning of my career, for example, methods sections would simply refer to "mice"; now at least we're usually told that they are male-alas, always male-C57BL/6 mice. Thus, it seems to me that the true reasons for poor translation lie elsewhere.

\section{What is responsible for poor translation?}

What then is responsible for our current translational challenges? Some believe that the drugs that work in animals really do also work in people, but that it's becoming harder and harder to prove this so. That is, the real problem may actually be the changing nature of clinical trials, in which fewer and fewer drug-naive participants are available, and in which the placebo response has steadily increased over time $\mathrm{e}^{11}$. Others have pointed to shortcomings in the validity

Departments of Psychology and Anesthesia and Alan Edwards Centre for Research on Pain, McGill University, Montreal, Canada. Correspondence should be addressed to J.S.M. (jeffrey.mogil@mcgill.ca). 
of animal models (and their implementation) used in preclinical studies ${ }^{12}$. I have previously argued that a major problem with the status quo in preclinical pain research is the animal models in common use; the inadequacies are related to all three facets of an animal model: subjects, assays, and measures ${ }^{13}$. The human sufferers of chronic pain are overwhelmingly female ${ }^{14}$, middle-aged or elderly ${ }^{15}$, and of heterogeneous genetic background, whereas the animal subjects in pain experiments are overwhelmingly young-adult, male Sprague Dawley rats or C57BL/6 mice ${ }^{13,16,17}$. Both quantitative and robust qualitative differences in pain processing have been documented between strains ${ }^{18}$ and the sexes ${ }^{19,20}$, confounding simple conclusions. The most common chronic pain syndromes in humans are low back pain, arthritis of the joints, and headache ${ }^{21}$, whereas the most common chronic pain assays in current use for animal subjects involve experimental ligations of afferent fibers serving, and injection of inflammatory substances into, the hind paw $^{22}$. Finally, whereas the most prevalent (and bothersome) clinical symptoms of chronic pain are deep, spontaneous (ongoing) pain and numbness ${ }^{23,24}$, and comorbidities like sleep disruption ${ }^{21}$, preclinical pain researchers continue to focus almost exclusively on measuring mechanical and thermal pain hypersensitivity (allodynia and hyperalgesia $)^{13,25}$. Whether currently popular animal models are close enough to clinical reality or not is hard to say (is the glass half-empty, or is it half-full?), and such discussions tend to quickly devolve into simply counting up recent efficacy successes (e.g., ziconotide, tanezumab) and failures (e.g., neurokinin-1 antagonists, fatty acid amide hydrolase inhibitors). Simply put, preclinical pain research with currently popular animal models performs more than adequately for backwards translation ${ }^{26,27}$; the forward translation jury is still out.

\section{The role of latent environmental factors in pain research}

I would suggest that another reason for apparent irreproducibility may be more important than is commonly appreciated: stealth or "latent" laboratory environmental factors ${ }^{28}$, the "unknown unknowns" of biology. Simply stated, any factor affecting stress levels in the testing environment may have huge effects on any biological phenomenon affected by stress, which includes essentially all of them, behavioral and non-behavioral alike. In turn, we are aware of only a few such factors, and even when we are aware of them they hardly ever receive our attention. Figure 1 lists a variety of factors that might vary in the laboratory environment, both in the vivarium and the testing room, that have been documented to affect pain sensitivity in rodents. Pain is, in fact, a perfect example of a biological domain in which subject stress can produce robust effects. The bigger problem is that these effects are unpredictable. Stress can produce either stressinduced analgesia (SIA) (see ref. 29 for review) or stress-induced hyperalgesia (SIH) (see ref. 30 for review), and although some evidence suggests that genetics, stress severity, context and chronicity may be relevant to the direction in which pain is modulated ${ }^{31-35}$, this topic remains greatly understudied. Also unappreciated is the fact that stress associated with pain testing can be surprisingly high (and hugely variable) in human participants as well. In a study of capsaicin pain, self-reported stress levels ranged from 0 to 8 on a 0 -to-10-point scale, and this stress interacted with both sex and a genetic variant within the AVPR1A gene to significantly affect pain ratings ${ }^{36}$.
Some laboratory stressors (or non-stressful modulatory factors) are related to husbandry, and have long been known. For example, housing isolation and crowding can both affect animal welfare (e.g., ref. 37), and directly affect pain sensitivity ${ }^{38-43}$, and the effects of cage density might be sex-specific ${ }^{44}$. Housing enrichment using physical objects has been shown to ameliorate pain ${ }^{45-47}$. Also well known are the effects of prenatal (i.e., gestational) stress (e.g., ref. 48) (which might be sex-specific ${ }^{49}$ ), which may occur due to noise or other disruptions in the breeding room, social isolation of breeding dams, or even high lead or arsenic levels in the drinking water ${ }^{50-52}$. Stress during pregnancy can affect maternal behavior ${ }^{53}$, which in turn can affect stress responses of rats in adulthood, and across generations ${ }^{54}$. Postnatal stressors during development can have long-lasting effects as well. Failure to provide bedding material for a rat to make a nest for her pups can lead to hyperalgesia in those pups when they become adults ${ }^{55,56}$, and the handling of young animals (for example, related to injections, and involving the stress of maternal separation) can cause long-term alterations in pain sensitivity ${ }^{41,57-63}$. A growing literature also documents the effect of diet on pain sensitivity ${ }^{64-80}$. In one case, differences in the soy content of rat chow turned out to be wholly responsible for a failure to replicate in Baltimore the findings of studies originally performed in Jerusalem ${ }^{65}$. Perhaps the largest husbandryrelated stressor is within-cage aggression in males. Social defeat in the "resident-intruder" assay is known to produce profound stress-induced analgesia ${ }^{81}$, and one might imagine great variability in the apparent "baseline" sensitivity of male mice depending on their social status (dominant/submissive) and how long before testing aggressive encounters had occurred. Kevin Keay and colleagues have shown that subpopulations of rats that exhibit dominant behavior as residents in a resident-intruder assay have different behavioral changes-including apparent changes in pain sensitivity-after nerve damage than rats that exhibit submissive behavior ${ }^{82}$, with corresponding alterations in neuroimmune signaling ${ }^{83}$. Even very subtle differences in husbandry may matter. One study demonstrated increased pain sensitivity of male mice reared until weaning with only their brothers compared to both brothers and sisters ${ }^{84}$. Another recent study observed that mice housed on aspen bedding were more sensitive to thermal and mechanical stimuli than mice housed on TEK-Fresh bedding made of $100 \%$ virgin wood pulp ${ }^{85}$. Other variable husbandry factors that have been discussed but not yet shown directly to affect pain sensitivity include: litter size (i.e., culling), weaning timing, light/dark phase duration, housing mice and rats in the same room, water source, in-house breeding versus commercial breeding (and, in the latter, delay between arrival and testing), direct transfer from vivarium to testing room versus the use of a holding room, and endemic presence of viruses. The effect of husbandry on adult biomedical testing is hardly limited to stress effects on behavioral measures. A celebrated recent study demonstrated that the hygienic barrier facilities that most laboratory mice are currently housed in render their immune system abnormally immature, and concludes that translation would be improved if mice were "dirtier"86. It should be pointed out that all these husbandry-related factors apply both to commercial breeding facilities as well as vivaria within academia and industry. 


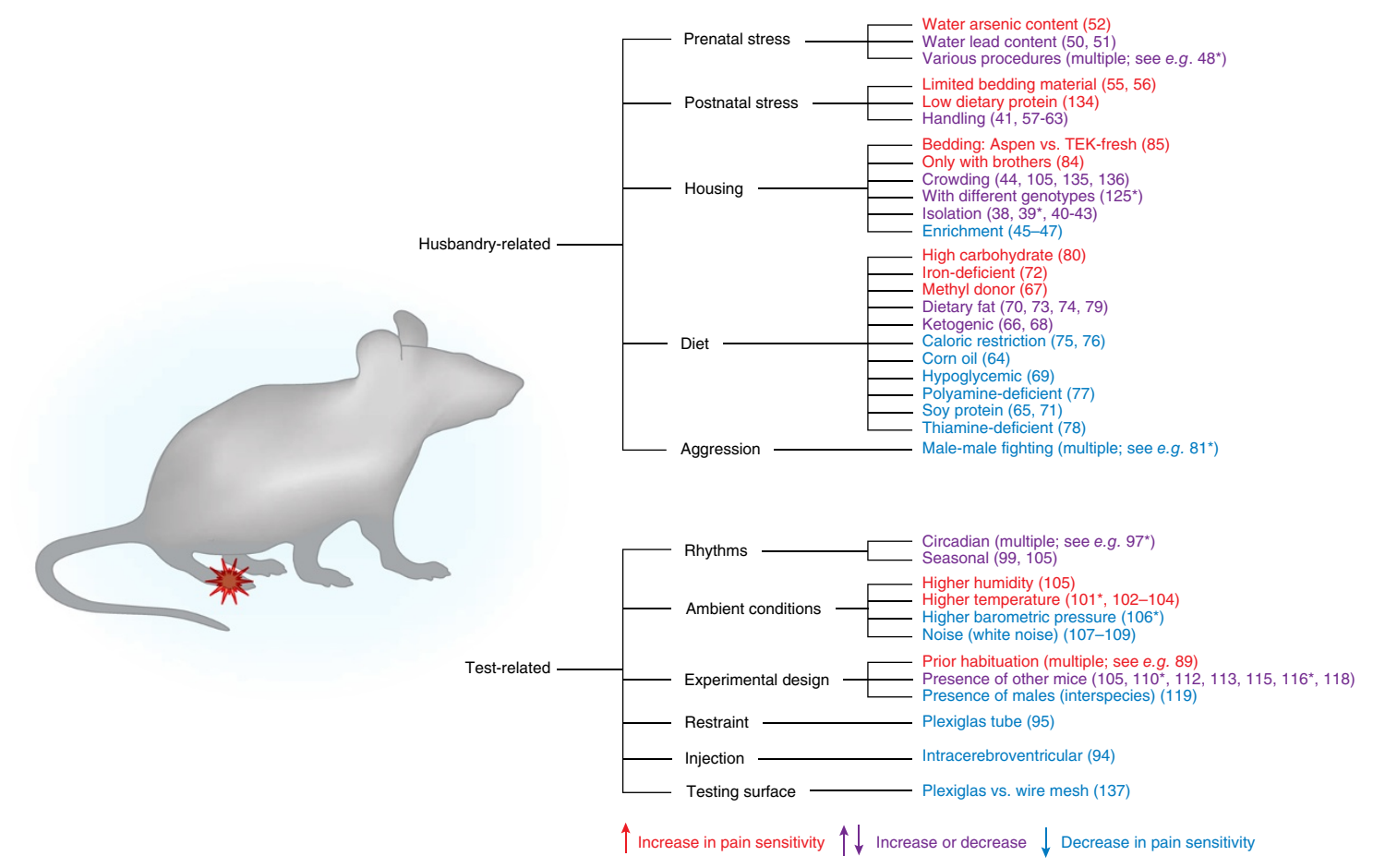

FIGURE 1 | Factors significantly affecting pain sensitivity in rodent models and sample references. Only factors that might credibly vary between laboratories are considered. For the factor "Diet", we excluded diabetes, hypertension and obesity models. We also excluded experimental stressors or procedures such as shock, restraint, prolonged maternal separation, or sucrose feeding. Only papers reporting statistically significant effects in either direction are listed. In the case of multiple papers by the same laboratory (indicated by *), only the first to be published is listed.

Other laboratory stressors occur in the testing room rather than the vivarium. Many routine procedures-including capture/ handling, blood collection, and gavage-produce stress in laboratory animals ${ }^{87}$. Simply being placed in a novel testing room under bright lights can produce non-negligible stress in laboratory mice that have never before left the vivarium ${ }^{88}$, and a large literature documents the SIA resulting from this novelty and the ameliorating effects of habituation to the testing room (e.g., ref. 89). Different laboratories have very different practices regarding the frequency and duration of handling of adult animals, potentially leading to very different (and strain-dependent ${ }^{90,91}$ ) stress levels on testing days if human experimenters are present during the data collection, and depending on whether the same or different individuals are involved in handling versus testing ${ }^{92}$. The precise method of mouse capture has been shown to have large effects on stress ${ }^{93}$. Stress related to injections, producing SIA, is well known ${ }^{28,94}$, and likely due to the associated capture and restraint ${ }^{95}$ required in addition to the needle itself. Whether animals are naive to other behavioral tests can affect the results of pain tests performed later ${ }^{96}$. Circadian rhythms affect pain in rodents (e.g., ref. 97), in a strain- ${ }^{98}$, sex- 99 and estrous phase-dependent ${ }^{100}$ manner, and testing times in laboratories vary widely, as does whether animals are kept under regular or reverse light cycles. The ambient temperature ${ }^{101-104}$, humidity ${ }^{105}$, barometric pressure ${ }^{106}$, and noise level ${ }^{107-109}$ in the testing room have all been shown to affect pain sensitivity; these are not as tightly controlled in many laboratories as is often pretended. In most cases, animals are tested in groups, and social factors can alter results as well. We and others have found that pain sensitivity can be increased (by emotional contagion ${ }^{110-113}$ or social SIH $^{88,111}$ ), or decreased (by social SIA ${ }^{88,110}$ or social buffering ${ }^{114-118}$ ) when animals are in close proximity (through either visual ${ }^{110}$ or olfactory ${ }^{113,119}$ mechanisms), depending on their social status (siblings, familiars, or strangers) and the threat level determined by their degree of physical access to each other. Our laboratory surprisingly observed that the mere presence of a male (but not female) experimenter in the testing room could produce stress in mice and rats, producing olfactory-mediated SIA that robustly affected apparent "baseline" pain sensitivity ${ }^{119}$.

\section{The impact of laboratory environmental factors}

That environmental factors differing from one laboratory to another can affect behavioral experiments has been appreciated for quite some time. In a famous study by Crabbe and colleagues ${ }^{120}$, the performance of multiple inbred mouse strains tested in standard behavioral assays were found to be highly lab-dependent, even though the investigators at three institutions took great pains to synchronize and standardize animal shipment, husbandry, and test-related parameters. It should be noted that the differences between labs were related to overall levels of behavior in these assays; relative strain sensitivities were generally preserved across sites $^{121}$. These investigators hypothesized that the lab variation was mostly due to "experimenter effects" 122 . In an analysis of acute pain sensitivity in over 8,000 mice we concluded that differences between experimenters accounted for more variance than any other factor, including genotype ${ }^{123}$. Environmental factors can interact with genotype, of course, producing yet more variability. In one experiment, 
investigators observed that a brief period of food shortage could abolish and even reverse a well-known mouse strain difference in response to amphetamine ${ }^{124}$. In an intriguing study of rats selectively bred for high and low pain (autotomy) behavior after hind limb denervation, the selected phenotype could be largely abolished simply by co-housing "high" rats with "low" counterparts, and viceversa $^{125}$. This same phenomenon was thereafter demonstrated in high- and low-autotomy mouse strains ${ }^{126}$. In one of our studies, a particularly robust strain difference in pain sensitivity ${ }^{127}$ was found eventually to exist only because of SIA-resulting simply from being placed in the testing room itself-in one strain but not the other; if mice were habituated to the room on several days before testing no strain difference was observed ${ }^{36}$.

These sorts of findings have led to a discussion as to whether reproducibility in animal experiments would be enhanced by standardization of husbandry and experimental parameters across laboratories $^{128}$. Some have argued for such standardization in the name of sample size reduction, and improving comparability of results within and between laboratories ${ }^{129}$. Others have pointed out that many environmental factors simply cannot be practically standardized (for example, staff, room architecture, noise, tap water composition, locally sourced rodent chow), and that any such attempts would prioritize comparability over the potentially even more important aim of generalizability (external validity) ${ }^{130,131}$. In fact, some have argued that attempts over the last few decades to standardize between laboratories in the name of reproducibility have actually led to a "standardization fallacy", producing results that are increasingly distinct between laboratories (and thus, perversely, less reproducible $)^{132}$. A proposed solution to the problem is systematic variation of experimental conditions ${ }^{128,133}$, although I see a real danger here in presupposing which environmental factors actually matter.

\section{Conclusions}

The plethora of "latent" laboratory environmental factors that affect pain studies - and biomedical studies more generally-imply that if two laboratories fail to replicate each other's findings, it is not necessarily the case that one is "right" and one is "wrong", or that such research is "irreproducible." They might both have obtained accurate data given their unique environmental context. The relevant contextual factors may or may not be appropriately reported, and may or may not even be understood. Increased prioritization, especially by funding agencies, of the identification of such factors (like experimenter sex, which was unknown until 2015) is warranted. Only by turning unknown unknowns into known knowns-and either controlling for them, covarying them out of statistical analyses, and/or explicitly varying them to investigate interactionswill we improve both the reproducibility and generalizability of preclinical research.

\section{COMPETING FINANCIAL INTERESTS}

The author declares no competing financial interests

\section{Received 21 0ctober 2016; accepted 15 November 2016}

Published online at http://www.nature.com/laban

1. Prinz, F., Schlange, T. \& Asadullah, K. Believe it or not: how much can we rely on published data on potential drug targets? Nat. Rev. Drug Discov. 10, 712 (2011).
2. Begley, C.G. \& Ellis, L.M. Drug development: raise standards for preclinical cancer research. Nature 483, 531-533 (2012).

3. Anonymous. How science goes wrong. The Economist, 0ctober 19-20 (2013).

4. Collins, F.S. \& Tabak, L.A. NIH plans to enhance reproducibility. Nature 505, 612-613 (2014).

5. Editors Announcement: reducing our irreproducibility. Nature 496, 398 (2013)

6. Open Science Collaboration. Estimating the reproducibility of psychological science. Science 349, aac4716 (2015).

7. Errington, T. M. et al. An open investigation of the reproducibility of cancer biology research. elife 3, e04333 (2014).

8. Baker, M. Is there a reproducibility crisis? Nature 533, 452-454 (2016).

9. Kola, I. \& Landis, J. Can the pharmaceutical industry reduce attrition rates? Nat. Rev. Drug Discov. 3, 711-716 (2004).

10. Jarvis, M.F. \& Williams, M. Irreproducibility in preclinical biomedical research: perceptions, uncertainties, and knowledge gaps. Trends Pharmacol. Sci. 37, 290-302 (2016).

11. Tuttle, A.H. et al. Increasing placebo responses over time in U.S. clinical trials of neuropathic pain. Pain 156, 2616-2626 (2015).

12. van der Worp, H.B. et al. Can animal models of disease reliably inform human studies? PLoS Med. 7, e1000245 (2010).

13. Mogil, J.S. Animal models of pain: progress and challenges. Nat. Rev. Neurosci. 10, 283-294 (2009).

14. Mogil, J.S. Sex differences in pain and pain inhibition: multiple explanations of a controversial phenomenon. Nat. Rev. Neurosci. 13, 859-866 (2012).

15. Gagliese, L. \& Melzack, R. Chronic pain in elderly people. Pain 70, 3-14 (1997).

16. Mogil, J.S. \& Chanda, M.L. The case for the inclusion of female subjects in basic science studies of pain. Pain 117, 1-5 (2005).

17. Mogil, J.S. Equality need not be painful. Nature 535, S7 (2016).

18. Mogil, J.S. et al. Variable sensitivity to noxious heat is mediated by differential expression of the CGRP gene. Proc. Natl. Acad. Sci. USA 102, 12938-12943 (2005).

19. Sorge, R.E. et al. Different immune cells mediate mechanical pain hypersensitivity in male and female mice. Nat. Neurosci. 18, 1081-1083 (2015).

20. Sorge, R.E. et al. Spinal cord Toll-like receptor 4 mediates inflammatory and neuropathic hypersensitivity in male but not female mice. J. Neurosci. 31, 15450-15454 (2011).

21. Institute of Medicine. Relieving Pain in America: A Blueprint for Transforming Prevention, Care, Education, and Research (National Academies Press, 2011).

22. Mogil, J.S. et al. Screening for pain phenotypes: analysis of three congenic mouse strains on a battery of nine nociceptive assays. Pain 126, 24-34 (2006).

23. Backonja, M.-M. \& Stacey, B. Neuropathic pain symptoms relation to overall pain rating. J. Pain 5, 491-497 (2004).

24. Scholz, J. et al. A novel tool for the assessment of pain: validation in low back pain. PLoS Med. 6, e1000047 (2009).

25. Mogil, J.S. \& Crager, S.E. What should we be measuring in behavioral studies of chronic pain in animals? Pain 112, 12-15 (2004).

26. Kontinen, V.K. \& Meert, T.F. in Proceedings of the 10th World Congress on Pain (eds J.0. Dostrovsky, D.B. Carr, \& M. Koltzenburg) 489-498 (IASP Press, 2002).

27. Whiteside, G.T., Adedoyin, A. \& Leventhal, L. Predictive validity of animal pain models? A comparison of the pharmacokinetic-pharmacodynamic relationship for pain drugs in rats and humans. Neuropharmacology 54 767-775 (2008).

28. Aydin, C., Frohmader, K. \& Akil, H. Revealing a latent variable: individual differences in affective response to repeated injections. Behav. Neurosci. 129, 679-682 (2015).

29. Butler, R.K. \& Finn, D.P. Stress-induced analgesia. Prog. Neurobiol. 88 184-202 (2009).

30. Imbe, H., Iwai-Liao, Y. \& Senba, E. Stress-induced hyperalgesia: animal models and putative mechanisms. Front. Biosci. 11, 2179-2192 (2006).

31. Cornelio, A.M., Mendes-Gomes, J., Fugimoto, J.S., Morgan, M.M. \& Nunes de Sousa, R.L. Environmentally induced antinociception and hyperalgesia in rats and mice. Brain Res. 1415, 56-62 (2011).

32. Gamaro, G.D. et al. The effects of acute and repeated restraint stress on the nociceptive response in rats. Physiol. Behav. 63, 693-697 (1998). 
33. Gameiro, G.H. et al. Nociception- and anxiety-like behavior in rats submitted to different periods of restraint stress. Physiol. Behav. 87, 643-649 (2006).

34. Illich, P.A., King, T.E. \& Grau, J.W. Impact of shock on pain reactivity: I. Whether hypo- or hyperalgesia is observed depends on how pain reactivity is tested. J. Exp. Psychol. 21, 331-347 (1995).

35. Jorum, E. Analgesia or hyperalgesia following stress correlates with emotional behavior in rats. Pain 32, 341-348 (1988).

36. Mogil, J.S. et al. Pain sensitivity and vasopressin analgesia are mediated by a gene-sex-environment interaction. Nat. Neurosci. 14, 1569-1573 (2011).

37. Arndt, S.S. et al. Individual housing of mice-Impact on behaviour and stress responses. Physiol. Behav. 97, 385-393 (2009).

38. Nishikawa, T. \& Tanaka, M. Altered behavioral responses to intense foot shock in socially-isolated rats. Pharmacol. Biochem. Behav. 8, 61-67 (1978)

39. Puglisi-Allegra, S. \& Oliverio, A. Social isolation: Effects on pain threshold and stress-induced analgesia. Pharmacol. Biochem. Behav. 19, 679-681 (1983).

40. Pitzer, C., Kuner, R. \& Tappe-Theodor, A. Voluntary and evoked behavioral correlates in neuropathic pain states under different housing conditions. Mol. Pain (in the press), 12 (2016).

41. Gentsch, C., Lichtsteiner, M., Frischknecht, H.-R., Feer, H. \& Siegfried, B. Isolation-induced locomotor hyperactivity and hypoalgesia in rats are prevented by handling and reversed by resocialization. Physiol. Behav. 43, 13-16 (1988).

42. Coudereau, J.-P., Monier, C., Bourre, J.-M. \& Frances, H. Effect of isolation on pain threshold and on different effects of morphine. Prog. Neuropsychopharmacol. Biol. Psychiatry 21, 997-1018 (1997).

43. Tuboly, G., Benedek, G. \& Horvath, G. Selective disturbance of pain sensitivity after social isolation. Physiol. Behav. 96, 18-22 (2009).

44. Brown, K.J. \& Grunberg, N.E. Effects of housing on male and female rats: crowding stresses males but calms females. Physiol. Behav. 58, 1085-1089 (1995).

45. Pham, T.M. et al. Housing environment influences the need for pain relief during post-operative recovery in mice. Physiol. Behav. 99, 663-668 (2010).

46. Gabriel, A.F. et al. Enriched environment and the recovery from inflammatory pain: social versus physical aspects and their interaction. Behav. Brain Res. 208, 90-95 (2010).

47. Tall, J.M. Housing supplementation decreases the magnitude of inflammation-induced nociception in rats. Behav. Brain Res. 197, 230-233 (2009).

48. Butkevich, I.P. \& Vershinina, E.A. Prenatal stress alters time characteristics and intensity of formalin-induced pain responses in juvenile rats. Brain Res. 915, 88-93 (2001).

49. Kinsley, C.H., Mann, P.E. \& Bridges, R.S. Prenatal stress alters morphineand stress-induced analgesia in male and female rats. Pharmacol. Biochem. Behav. 30, 123-128 (1988).

50. Jackson, H.C. \& Kitchen, I. Perinatal lead exposure impairs opioid but not non-opioid stress-induced antinociception in developing rats. Br. J. Pharmacol. 97, 1338-1342 (1989).

51. Vickers, C. \& Paterson, A.T. Two types of chronic lead treatment in C57BL/6 mice: interaction with behavioural determinants of pain. Life Sci. 39, 47-53 (1986).

52. Aguirre-Banuelos, P., Escudero-Lourdes, C., Sanchez-Pena, L.C., Del Razo, L.M. \& Perez-Urizar, J. Inorganic arsenic exposure affects pain behavior and inflammatory response in rat. Toxicol. Appl. Pharmacol. 229, 374-385 (2008).

53. Patin, V. et al. Effects of prenatal stress on maternal behavior in the rat. Brain Res. Dev. Brain Res. 139, 1-8 (2002).

54. Francis, D., Diorio, J., Liu, D. \& Meaney, M.J. Nongenomic transmission across generations of maternal behavior and stress responses in the rat. Science 286, 1155-1158 (1999).

55. Guo, Y., Wang, Z., Mayer, E.A. \& Holschneider, D.P. Neonatal stress from limited bedding elicits visceral hyperalgesia in adult rats. Neuroreport 26, 13-16 (2015).

56. Alvarez, P., Green, P.G. \& Levine, J.D. Stress in the adult rat exacerbates muscle pain induced by early-life stress. Biol. Psychiatry 74, 688-695 (2013).

57. Pieretti, S., d'Amore, A. \& Loizzo, A. Long-term changes induced by developmental handling on pain threshold: effects of morphine and naloxone. Behav. Neurosci. 105, 215-218 (1991).
58. d'Amore, A., Mazzucchelli, A. \& Loizzo, A. Long-term changes induced by neonatal handling in the nociceptive threshold and body weight in mice. Physiol. Behav. 57, 1195-1197 (1995).

59. Clausing, P., Mothes, H.K., Opitz, B. \& Kormann, S. Differential effects of communal rearing and preweaning handling on open-field behavior and hot-plate latencies in mice. Behav. Brain Res. 82, 179-184 (1997).

60. Sternberg, W.F. \& Ridgway, C.G. Effects of gestational stress and neonatal handling on pain, analgesia, and stress behavior of adult mice. Physiol. Behav. 78, 375-383 (2003).

61. Smythe, J.W., McCormick, C.M., Rochford, J. \& Meaney, M.J. The interaction between prenatal stress and neonatal handling on nociceptive response latencies in male and female rats. Physiol. Behav. 55, 971-974 (1994).

62. Alvarez, P., Levine, J.D. \& Green, P.G. Neonatal handling (resilience) attenuates water-avoidance stress induced enhancement of chronic mechanical hyperalgesia in the rat. Neurosci. Lett. 591, 207-211 (2015).

63. Fernandez, B., Alberti, I., Kitchen, I. \& Viveros, M.P. Neonatal naltrindole and handling differently affect morphine antinociception in male and female rats. Pharmacol. Biochem. Behav. 64, 851-855 (1999).

64. Frye, C.A., Cuevas, C.A. \& Kanarek, R.B. Diet and estrous cycle influence pain sensitivity in rats. Pharmacol. Biochem. Behav. 45, 255-260 (1993).

65. Shir, Y., Ratner, A., Raja, S.N., Campbell, J.N. \& Seltzer, Z. Neuropathic pain following partial nerve injury in rats is suppressed by dietary soy. Neurosci. Lett. 240, 73-76 (1998).

66. Ziegler, D.R. et al. Nociception and locomotor activity are increased in ketogenic diet fed rats. Physiol. Behav. 84, 421-427 (2005).

67. Sun, Y., Liang, D., Sahbaie, P. \& Clark, J.D. Effects of methyl donor diets on incisional pain in mice. PLOS ONE 8, e77881 (2013).

68. Ruskin, D.N., Suter, T.A., Ross, J.L. \& Masino, S.A. Ketogenic diets and thermal pain: dissociation of hypoalgesia, elevated ketones, and lowered glucose in rats. J. Pain 14, 467-474 (2013).

69. Ross-Huot, M.-C. et al. Effects of glycemic regulation on chronic postischemia pain. Anesthesiology 115, 614-625 (2011).

70. Veigas, J.M. et al. Fish oil concentrate delays sensitivity to thermal nociception in mice. Pharmacol. Res. 63, 377-382 (2011).

71. Borzan, J., Tall, J.M., Zhao, C., Meyer, R.A. \& Raja, S.N. Effects of soy diet on inflammation-induced primary and secondary hyperalgesia in rat. Eur. J. Pain 14, 792-798 (2010).

72. Dowling, P., Klinker, F., Amaya, F., Paulus, W. \& Liebetanz, D. Iron-deficiency sensitizes mice to acute pain stimuli and formalin-induced nociception. J. Nutr. 139, 2087-2092 (2009).

73. Martin, Y.B. \& Avendano, C. Effects of removal of dietary polyunsaturated fatty acids on plasma extravasation and mechanical allodynia in a trigeminal neuropathic pain model. Mol. Pain 5, 8 (2009).

74. Perez, J., Ware, M.A., Chevalier, S., Gourgeon, R. \& Shir, Y. Dietary omega-3 fatty acids may be associated with increased neuropathic pain in nerve-injured rats. Anesth. Analg. 101, 444-448 (2005).

75. Hargraves, W.A. \& Hentall, I.D. Analgesic effects of dietary caloric restriction in adult mice. Pain 114, 455-461 (2005).

76. de los Santos-Arteaga, M., Sierra-Dominguez, S.A., Fontanella, G.H., Delgado-Garcia, J.M. \& Carrion, A.M. Analgesia induced by dietary restriction is mediated by the $\mathrm{K}$-opioid system. J. Neurosci. 23, 11120-11126 (2003).

77. Kergozien, S., Bansard, J.Y., Delcros, J.G., Havouis, R. \& Moulinoux, J.P. Polyamine deprivation provokes an antalgic effect. Life Sci. 58, 2209-2215 (1996).

78. Tadano, T. et al. Immunohistochemical determination of rat spinal cord substance $P$, and antinociceptive effect during development of thiamine deficiency. Brain Res. 696, 21-29 (1995).

79. Yehuda, S. \& Carasso, R.L. Effects of dietary fat on pain threshold, thermoregulation and motor activity in rats. Pharmacol. Biochem. Behav. 24, 1775-1777 (1986).

80. Totsch, S.K. et al. Total Western Diet alters mechanical and thermal sensitivity and prolongs hypersensitivity following complete Freund's adjuvant in mice. J. Pain 17, 119-125 (2016).

81. Miczek, K.A., Thompson, M.L. \& Shuster, L. Opioid-like analgesia in defeated mice. Science 215, 1520-1522 (1982).

82. Monassi, C.R., Bandler, R. \& Keay, K.A. A subpopulation of rats show social and sleep-waking changes typical of chronic neuropathic pain following peripheral nerve injury. Eur. J. Neurosci. 17, 1907-1920 (2003). 
83. Austin, P.J. et al. Evidence for a distinct neuro-immune signature in rats that develop behavioural disability after nerve injury. J. Neuroinflammation 12, 96 (2015).

84. Alleva, E., Caprioli, A. \& Laviola, G. Postnatal social environment affects morphine analgesia in male mice. Physiol. Behav. 36, 779-781 (1986).

85. Moehring, F., O'Hara, C.L. \& Stucky, C.L. Bedding material affects mechanical thresholds, heat thresholds, and texture preference. J. Pain 17, 50-64 (2016).

86. Beura, L.K. et al. Normalizing the environment recapitulates adult human immune traits in laboratory mice. Nature 532, 512-516 (2016).

87. Balcombe, J.P., Barnard, N.D. \& Sandusky, C. Laboratory routines cause animal stress. Contemp. Top. Lab. Anim. Sci. 43, 42-51 (2004).

88. Langford, D.L. et al. Varying perceived social threat modulates pain behavior in male mice. J. Pain 12, 125-132 (2011).

89. Abbott, F.V., Franklin, K.B.J. \& Connell, B. The stress of a novel environment reduces formalin pain: possible role of serotonin. Eur. J. Pharmacol. 126, 141-144 (1986).

90. Ryabinin, A.E., Wang, Y.-M. \& Finn, D.A. Different levels of Fos immunoreactivity after repeated handling and injection stress in two inbred strains of mice. Pharmacol. Biochem. Behav. 63, 143-151 (1999).

91. Wahlsten, D., Metten, P. \& Crabbe, J.C. A rating scale for wildness and ease of handling laboratory mice: results for 21 inbred strains tested in two laboratories. Genes Brain Behav. 2, 71-79 (2003).

92. Davis, H. Prediction and preparation: Pavlovian implications of research animals discriminating among humans. ILAR J. 43, 19-26 (2002).

93. Hurst, J.L. \& West, R.S. Taming anxiety in laboratory mice. Nat. Methods 7, 825-826 (2010)

94. Mogil, J.S. et al. Orphanin FQ is a functional anti-opioid peptide. Neuroscience 75, 333-337 (1996).

95. Mogil, J.S., Wilson, S.G. \& Wan, Y. in Methods in Pain Research (ed L. Kruger) 11-39 (CRC Press, 2001).

96. McIlwain, K.L., Merriweather, M.Y., Yuva-Paylor, L.A. \& Paylor, R. The use of behavioral test batteries: effects of training history. Physiol. Behav. 73, 705-717 (2001).

97. Frederickson, R.C., Burgis, V. \& Edwards, J.D. Hyperalgesia induced by naloxone follows diurnal rhythm in responsivity to painful stimuli. Science 198, 756-758 (1977).

98. Castellano, C., Puglisi-Allegra, S., Renzi, P. \& Oliverio, A. Genetic differences in daily rhythms of pain sensitivity in mice. Pharmacol. Biochem. Behav. 23, 91-92 (1985).

99. Perissin, L., Facchin, P. \& Porro, C.A. Tonic pain response in mice: effects of sex, season and time of day. Life Sci. 72, 897-907 (2003).

100. Martinez-Gomez, M., Cruz, Y., Salas, M., Hudson, R. \& Pacheco, P. Assessing pain threshold in the rat: changes with estrus and time of day. Physiol. Behav. 55, 651-657 (1994).

101. Berge, 0.G., Garcia-Cabrera, I. \& Hole, K. Response latencies in the tail-flick test depend on tail skin temperature. Neurosci. Lett. 86, 284-288 (1988).

102. Rosland, J.H. The formalin test in mice: the influence of ambient temperature. Pain 45, 211-216 (1991).

103. Pincede, I., Pollin, B., Meert, T., Plaghki, L. \& Le Bars, D. Psychophysics of a nociceptive test in the mouse: ambient temperature as a key factor for variation. PLOS ONE 7, e36699 (2012).

104.Vitkova, J., Loucka, M., Bocek, J. \& Vaculin, S. The effect of acclimatization and ambient temperature on heat withdrawal threshold in rats. Eur. J. Pain 19, 21-27 (2015).

105. Chesler, E.J., Wilson, S.G., Lariviere, W.R., Rodriguez-Zas, S.L. \& Mogil, J.S. Identification and ranking of genetic and laboratory environment factors influencing a behavioral trait, thermal nociception, via computational analysis of a large data archive. Neurosci. Biobehav. Rev. 26, 907-923 (2002).

106. Sato, J. et al. Lowering barometric pressure aggravates mechanical allodynia and hyperalgesia in a rat model of neuropathic pain. Neurosci. Lett. 266, 21-24 (1999).

107.Chen, Y.-F., Chiang, H.-M., Tsai, Y.-T. \& Tsai, H.-Y. Association of increased pain threshold by noise with central opioid neurons. Chin. J. Physiol. 52, 93-98 (2009).

108. Shankar, N., Awasthy, N., Mago, H. \& Tandon, O.P. Analgesic effect of environmental noise: a possible stress response in rats. Indian J. Physiol. Pharmacol. 43, 337-346 (1999).

109. Helmstetter, F.J. \& Bellgowan, P.S. Hypoalgesia in response to sensitization during acute noise stress. Behav. Neurosci. 108, 177-185 (1994).
110. Langford, D.L. et al. Social modulation of pain as evidence for empathy in mice. Science 312, 1967-1970 (2006).

111. Martin, L.J. et al. Reducing social stress elicits emotional contagion of pain in mouse and human strangers. Curr. Biol. 25, 326-332 (2015).

112. Baptista-de-Souza, D. et al. Mice undergoing neuropathic pain induce anxiogenic-like effects and hypernociception in cagemates. Behav. Pharmacol. 26, 664-672 (2015).

113.Smith, M.L., Hostetler, C.M., Heinricher, M.M. \& Ryabinin, A.E. Social transfer of pain in mice. Sci. Adv. 2, e1600855 (2016).

114. Langford, D.L. et al. Social approach to pain in laboratory mice. Soc. Neurosci. 5, 163-170 (2010).

115. Agren, G., Uvnas-Moberg, K. \& Lundeberg, T. Olfactory cues from an oxytocin-injected male rat can induce anti-nociception in its cagemates. Neuroreport 8, 3073-3076 (1997).

116.D'Amato, F.R. \& Pavone, F. Endogenous opioids: a proximate reward mechanism for kin selection? Behav. Neural Biol. 60, 79-83 (1993).

117. D'Amato, F.R. \& Pavone, F. Reunion of separated sibling mice: neurobiological and behavioral aspects. Neurobiol. Learn. Mem. 65, 9-16 (1996).

118. Gioiosa, L., Chiarotti, F., Alleva, E. \& Laviola, G. A trouble shared is a trouble halved: social context and status affect pain in mouse dyads. PLOS ONE 4, e4143 (2009).

119. Sorge, R.E. et al. Olfactory exposure to males, including human males, stresses rodents. Nat. Methods 11, 629-632 (2014).

120. Crabbe, J.C., Wahlsten, D. \& Dudek, B.C. Genetics of mouse behavior: interactions with laboratory environment. Science 284, 1670-1672 (1999).

121. Wahlsten, D., Bachmanov, A., Finn, D.A. \& Crabbe, J.C. Stability of inbred mouse strain differences in behavior and brain size between laboratories and across decades. Proc. Natl. Acad. Sci. USA 103, 16364-16369 (2006).

122. Bohlen, M. et al. Experimenter effects on behavioral test scores of eight inbred mouse strains under the influence of ethanol. Behav. Brain Res. 272, 46-54 (2014).

123.Chesler, E.J., Wilson, S.G., Lariviere, W.R., Rodriguez-Zas, S.L. \& Mogil, J.S. Influences of laboratory environment on behavior. Nat. Neurosci. 5 , 1101-1102 (2002).

124.Cabib, S., Orsini, C., Le Moal, M. \& Piazza, P.V. Abolition and reversal of strain differences in behavioral responses to drugs of abuse after a brief experience. Science 289, 463-465 (2000).

125. Raber, P. \& Devor, M. Social variables affect phenotype in the neuroma model of neuropathic pain. Pain 97, 139-150 (2002).

126. Devor, M. et al. Sex-specific variability and a 'cage effect' independently mask a neuropathic pain quantitative trait locus detected in a whole genome scan. Eur. J. Neurosci. 26, 681-688 (2007).

127. Mogil, J.S., Lichtensteiger, C.A. \& Wilson, S.G. The effect of genotype on sensitivity to inflammatory nociception: characterization of resistant (A/J) and sensitive (C57BL/6) inbred mouse strains. Pain 76, 115-125 (1998).

128. Richter, S.H., Garner, J.P. \& Wurbel, H. Environmental standardization: cure or cause of poor reproducibility in animal experiments? Nat. Methods 6, 257-261 (2009).

129. Beynen, A.C., Gartner, K. \& van Zufphen, L.F.M. in Principles of Laboratory Animal Science (eds L.F.M. Van Zutphen, V. Baumans, \& A.C. Beynen) 103-110 (Elsevier, 2001).

130. Wurbel, H. Behavioral phenotyping enhanced - beyond (environmental) standardization. Genes Brain Behav. 1, 3-8 (2002).

131. Wahlsten, D. Standardizing tests of mouse behavior: reasons, recommendations, and reality. Physiol. Behav. 73, 695-704 (2001).

132. Wurbel, H. Behaviour and the standardization fallacy. Nat. Genet. 26, 263 (2000).

133. Richter, S.H. et al. Effect of population heterogenization on the reproducibility of mouse behavior: a multi-laboratory study. PLOS ONE 6, e16461 (2011).

134. Rocinholi, L.F., Almeida, S.S. \& De-Oliveira, L.M. Response threshold to aversive stimuli in stimulated early protein-malnourished rats. Braz. J. Med. Biol. Res. 30, 407-413 (1997).

135.Pilcher, C.W.T. \& Browne, J. Environmental crowding modifies responding to noxious stimuli and the effects of $\mu$ - and $\kappa$-agonists. Life Sci. 31, 1213-1216 (1982).

136. Tramullas, M., Dinan, T.G. \& Cryan, J.F. Chronic psychosocial stress induces visceral hyperalgesia in mice. Stress 15, 281-292 (2012).

137. Pitcher, G.M., Ritchie, J. \& Henry, J.L. Paw withdrawal threshold in the von Frey hair test is influenced by the surface on which the rat stands. J. Neurosci. Methods 87, 185-193 (1999). 